\title{
GPs' and health visitors' views on the diagnosis and management of postnatal depression: a qualitative study
}

Carolyn Chew-Graham, Elizabeth Chamberlain, Katrina Turner, Liz Folkes, Layne Caulfield and Deborah Sharp

\begin{abstract}
Background

In the UK, 8-15\% of women suffer from postnatal depression, with long-term consequences for maternal mood and child development. Previous literature suggests that health visitors struggle with their conflicting roles with respect to mother and infant. Current policy is redirecting the emphasis and organisation of health visitor work, but guidelines state that health visitors and GPs should continue to have a major role in the detection and management of postnatal depression.

Aim
\end{abstract}

To explore the views of GPs and health visitors on the diagnosis and management of postnatal depression.

\section{Design of study}

A qualitative study nested within a multicentre randomised controlled trial.

\section{Setting}

Nine primary care trusts in Bristol, Manchester, and

London.

Method

In-depth interviews with GPs and health visitors from primary care trusts participating in a randomised controlled trial of antidepressants versus health visitordelivered non-directive counselling. Interviews were audiotaped and fully transcribed. Thematic analysis with an iterative approach was used to develop conceptual categories from the transcripts.

\section{Results}

Nineteen GPs and 14 health visitors were interviewed. GPs and health visitors described their work in making and negotiating the diagnosis of postnatal depression, the value of a long-term relationship with the woman, and how labelling affects management of women with postnatal depression. Responders described how they viewed others' roles in the management of postnatal depression, and how national policy and loca organisational changes had an impact on patient care, so that no one health professional was assuming overall responsibility for the care of women with postnatal depression.

\section{Conclusion}

Ongoing organisational changes within primary care, such as the implementation of corporate working by health visitors, affect care provided to women after birth, which in turn has an impact on the diagnosis and management of postnatal depression.

\section{Keywords}

health visitors; qualitative research; postnatal depression; primary care.

\section{INTRODUCTION}

Postnatal depression is one of the core diagnoses in the National Service Framework (NSF) for Mental Health, ${ }^{1}$ and represents a substantial public health problem affecting $8-15 \%$ of women, resulting in longterm adverse consequences for maternal mood and infant development. ${ }^{2}$ Postnatal depression is a nonpsychotic depressive episode meeting standardised diagnostic criteria for a minor or major depressive disorder, beginning in, or extending to the postnatal period. ${ }^{3}$ An episode of major depression may have detrimental consequences for the family, erode already difficult marital relationships, and reduce confidence in parenting. Most women with postnatal depression are treated within primary care, with only severe cases or women with psychosis or suicidal intent being referred to secondary care. The recently published National Institute for Health and Clinical Excellence (NICE) guidelines for antenatal and

C Chew-Graham, MD, FRCGP, senior lecturer in primary care, School of Community-Based Medicine, University of Manchester; and National School for Primary Care Research, National Institute of Health Research, UK. E Chamberlain, $B S c$, research associate, Centre for Women's Studies, University of Manchester. K Turner; BSc, MSc, PhD, lecturer; D Sharp, PhD, FRCGP, professor of primary health care, Academic Unit of Primary Health Care, University of Bristol; and National School for Primary Care Research, National Institute of Health Research, UK. L Folkes, BSc, RGN, MSc, research associate, Academic Unit of Primary Health Care, University of Bristol. L Caulfield, MB ChB, foundation year doctor, North West Deanery.

Address for correspondence

Dr Carolyn Chew-Graham, University of Manchester, School of Community-Based Medicine, Rusholme Academic Unit, Walmer Street, Manchester, M14 5NP.

E-mail: cchew@manchester.ac.uk

Submitted: 23 July 2007; Editor's response: 18 September 2007; final acceptance: 2 November 2007.

(c)British Journal of General Practice 2008; 58: 169-176.

DOI: 10.3399/bjgp08X277212 


\section{How this fits in}

In the UK, 8-15\% women suffer from postnatal depression with long-term consequences for maternal mood and child development. Postnatal depression is predominantly managed in UK primary care by GPs and health visitors. Previous literature suggests that health visitors struggle with their conflicting roles with respect to mother and infant. Current policy is redirecting the emphasis of health visiting work away from the management of postnatal depression. This paper highlights the need to reconsider health service provision for women in the perinatal period. It is necessary to be explicit about where the responsibility for detection and diagnosis of postnatal depression lies. The paper adds support to the recently published National Institute for Health and Clinical Excellence (NICE) guidelines that advocate specialist multidisciplinary teams to provide a service for women with postnatal depression.

postnatal mental health use the term 'perinatal mental disorder', recognising that symptoms may begin in the antenatal period, and outline the potential role of all healthcare professionals in the detection of depression. ${ }^{4}$ The guidelines suggest the establishment of specialist multidisciplinary perinatal services in each locality, but until the commissioning of such services, health visitors and GPs should continue to have a major role in the detection and management of perinatal depression.

There is some evidence that lay constructs about postnatal depression differ from medical views, in terms of the conceptualisation of postnatal depression, and therefore of help seeking. ${ }^{5}$ There is evidence that the construction of 'depression' as a clinical condition is contested among GPS, 6,7 but there is little published work on the role played by GPs in the management of postnatal depression. There is evidence that health visitors conceptualise postnatal depression as an understandable result of parenting in a hostile world, and that they struggle with their conflicting roles with respect to mother and infant, ${ }^{8}$ with a lack of clarity over who is the patient.

The health visiting profession is said to owe its emergence to the pioneer work of able medical officers of health rather than to central government policy. $^{9}$ Health visiting became intertwined with parenting and supporting parents, both with individual families and by addressing the social context in which 'parenting' takes place. ${ }^{10,11}$

The role of the health visitor in the management of postnatal depression was shaped by the development of training for health visitors in the prevention, detection, and treatment of postnatal depression. $^{12,13}$ It has been suggested that health visitors should screen for postnatal depression using the Edinburgh Postnatal Depression Scale. ${ }^{14,15}$ Cooper and Murray state that the treatment of choice for women with postnatal depression is counselling, ${ }^{16}$ which can be effectively delivered by health visitors. ${ }^{17}$
In contrast, Boath and Henshaw conclude that there is very little good evidence available on which to make policy or practice recommendations for the treatment of postnatal depression. ${ }^{18}$

More recently, the pressure on health professionals to be more explicit in articulating the function, purpose, and outcome of their role has increased and there has been a shift to a marketplace orientation with the implementation of the NHS and Community Care Act 1990. Cowley describes how health visitors have had continued difficulty explaining exactly what they do, although she sees this as an advantage, suggesting that the management of uncertainty and ambiguity are central to their role. ${ }^{19}$

The role of health visitors in safeguarding children ${ }^{20}$ and working with vulnerable families emphasises their importance in public health initiatives such as tackling childhood obesity. There is reduced emphasis on one-to-one working with families who are not deemed 'at risk', and working with women with postnatal depression has dropped down the policy agenda. ${ }^{20}$ The NICE guidelines do not emphasise a pivotal role for health visitors or GPs in the management of perinatal mental health problems. ${ }^{4}$

There has been a move towards health visitor 'corporate working', with the benefits described by Houston and Clifton including shared workload, increased professional support, and improved accountability with improved service delivery, enhanced professional growth, and increased opportunity for public health work as outcomes of this model. ${ }^{21}$ Derrett and Burke describe how other current UK policy directives, encouraging alternative ways of working and alternative provider services, all threaten traditional primary care teams, and raise questions about the future of health visiting. ${ }^{22}$ The number of health visitors is at its lowest for 12 years, ${ }^{23}$ and the emphasis on changing skill mix is seen as evidence of the decline of the role of health visitors. An online patient support group, Netmums, highlights this change and the reduction in the number of health visitors offering one-to-one support to women after childbirth and their declining role in the management of postnatal depression. ${ }^{24}$

This paper presents findings from a qualitative study with GPs and health visitors which explored their views on their roles in the detection and management of postnatal depression, and how this was affected by their current working arrangements dictated by national policy directives.

\section{METHOD}

A qualitative study was undertaken within a multicentre, pragmatic, randomised controlled trial (the RESPOND trial, [Randomised Evaluation of antidepressants and Support for women with 
POstNatal Depression]). Nine primary care trusts (PCTs) took part in the trial in Bristol, Manchester, and London, and general practices were invited to opt into the study. The nine trusts covered inner-city and urban areas with some areas of very high levels of deprivation, particularly in Manchester. Sure Start programmes were located in pockets of the participating PCTs in Manchester and London. ${ }^{25}$

In-depth interviews were carried out with GPs and health visitors. Their purpose was to explore the attitudes GPs and health visitors held towards women with postnatal depression and management in primary care. The sample was drawn from GPs and health visitors participating in the RESPOND trial. Sampling was purposive and sought to achieve maximum variation in relation to GPs' age, sex, length of time in general practice, practice size, and level of deprivation. An attempt was made to interview GPs who had and who had not referred patients to the trial. Sampling of health visitors was also purposive so that variation was achieved in relation to time since completion of training, and length of service in that area, as well as level of engagement with the trial. At the start of the main trial, most health visitors were practice based, but corporate working was introduced to all areas during the first year of the study. An attempt was made to interview health visitors who were still practice based, as well as those who had been moved to a corporate way of working. Thirtyseven GPs were approached by letter and telephone and 19 agreed to be interviewed. Twenty health visitors employed within participating PCTs were invited to participate and 14 agreed to be interviewed.

In-depth interviews were conducted between January 2006 and February 2007. Participants were interviewed at their place of work, and interviews lasted between 25-67 minutes. An interview guide provided a flexible framework for questioning, and explored a number of topics: models of postnatal depression; diagnosis and management of postnatal depression; and the patient-professional relationship, professional-professional relationships, and ways of working. The interview guide included open questions to elicit free responses, and more-focused questions for probing and prompting. Interviews were audiorecorded and transcribed verbatim.

Analysis proceeded in parallel with the interviews, allowing for modification of the interview schedule in the light of emerging themes. Analysis was inductive and a thematic approach taken. ${ }^{26}$ Transcripts were read and discussed by researchers from different professional backgrounds (primary care and psychology). ${ }^{27}$ Coding was informed by the accumulating data and continuing thematic analysis. Thematic categories were identified in initial interviews, which were then tested or explored in subsequent interviews where disconfirmatory evidence was sought. ${ }^{26}$ Interpretation and coding of data was undertaken independently with themes agreed through discussion.

In reporting the final analysis, data were presented to illustrate the range and commonality of meaning of each category of analysis from the perspectives of GPs and health visitors. In presenting the data, similarities and differences between GP and health visitor accounts were noted.

\section{RESULTS}

A number of themes are discussed in this paper: making and negotiating the diagnosis of postnatal depression, how labelling can affect management, the importance of an established relationship with the woman, perceptions of each others' roles, and how imposed organisational changes were seen to have an impact on patient care with no one taking overall responsibility for the care of women with postnatal depression. Illustrative data are presented within each theme. When reproducing data, a unique identifier has been given to indicate the responder's profession, location, and interview number.

\section{Making the diagnosis}

All responders attributed a psychosocial aetiology to postnatal depression and demonstrated ambivalence about the status of postnatal depression as a separate condition:

'I call it emotional turmoil rather than depression ... psychological disturbance, at various stages after the birth, and I don't think of them as adjustment disorders, and often they are what I would think of as 'existential crises'.' (GP, M1)

'I can certainly give you a list of things that would put women at risk, but, you know, clearly doesn't always result in PND [postnatal depression]. So a previous history of mental health problems or depression, unfulfilled expectation, difficult birth, wrong sex, partner unsupportive ... but, I think there's quite a large proportion where there appears to be no risk factors.' (HV, B2)

GPs and health visitors described a reliance on instinct or clinical intuition which would alert them to the possibility of postnatal depression; they did not then go on to use a schedule such as the Edinburgh Postnatal Depression Scale. Neither did they use such a schedule to screen women:

'So I'm not saying I actively look for it, but I am hoping my antennae would tell me if there was a problem.' (GP, M5) 
'I think any kind of flatness ... it's a difficult thing to explain, isn't it? ... You can just tell by having a conversation ... just chatting to them.' (HV, B1)

Thus, postnatal depression was viewed as a social response to birth and there was an apparent reluctance by GPs and health visitors to actively look for depression in postnatal women.

\section{Labelling affects management}

GPs described a variety of strategies for managing women in the postnatal period, and how the label they used for the woman's problems determined what management strategies they employed:

'It's about normalising how they think ... I don't always offer anything ... I very rarely prescribe on the first visit ... so I think many depressions are like PND actually, they exist in the context of somebody's life and it has a meaning for them which you have to attend to ... I hate these things where they say if you've got five tick-boxes then you have 6 months of fluoxetine, that's gross.' (GP, M1)

'I don't want to medicalise it too much really I think it needs to be an informal sort of network because I do think most of the time people do recover from it if they are just given some support rather than medication.' (GP, M8)

The use of the term 'medicalise' by GPs is interesting, as it is normally a term used in the context of using a medical label to describe what are probably non-biomedical problems. Here the GPs are describing a reluctance to recognise and treat a condition that may actually warrant a biomedical approach. GPs were reluctant to ascribe a biomedical label to women with symptoms that could indicate postnatal depression because they perceived there was a lack of resources to which they could refer women:

If I call it depression, I need to do something. There's no one to refer to, so I would rather call it something else and manage her myself.' (GP, M10)

Health visitors, although reluctant themselves to make a diagnosis of postnatal depression, suggested that using a label of depression could be beneficial for the woman:

'I mean some would probably like to have a label put on it if they're feeling unwell, at least it's a recognised sort of thing isn't it, that they can say "well l've got this".' (HV, M4)
This could suggest that health visitors might be more comfortable with managing a woman whose symptoms have been given a name. Some health visitors, however, suggested that by using the label 'depression' the woman would then have to see her GP, and that the woman would assume seeing her GP meant the prescription of an antidepressant:

'Because I think they think that seeing a GP means having medication and they don't wanna have medication because of addiction ... a lot of women don't want to get addicted to it, and I think also probably don't like the stigma of being, er, having postnatal depression ...'

(HV, B3)

\section{Is an established relationship important?}

Some health visitors recognised that having an established relationship with a woman was important in whether postnatal depression was detected and managed by the health professional or disclosed by the woman, but there was ambivalence:

'... I think that is quite important, but I don't think it's the be all and end all, I really don't. I think some health visitors get a bit precious about, you know, "my client", and all that.'

(HV, L5)

All health visitors referred to how recent changes in their way of working, moving to corporate working, had removed the potential for relationships to be ongoing, which had a direct impact on the detection of postnatal depression:

'... but I think they used to get to know us, and we used to get to know them and obviously if they know someone they're more likely to sort of be forthcoming with any problems aren't they? Whereas now they probably don't get that input so they're probably less likely to come forward with things.' (HV, M4)

\section{Perceptions of others' roles}

Some GPs emphasised the important role health visitors could play in the management of postnatal depression and their assumptions about how they worked:

'I think it depends very much on the skills and the experience of the health visitor but I think very much about helping the women too. Providing some sort of support, I guess, someone to talk to and listen to but also perhaps, one hopes, that you are giving people some structure and some practical things to do 
in order to maybe to cope with crying babies and, you know, poor sleep, and perhaps lack of support in the house.' (GP, M10)

Other GPs reported observing an unwillingness of health visitors to manage women with postnatal depression:

'... because I think they seem very constrained on what they are prepared to do really. I think that they seem just to play not a very noninterventionalist role and see themselves as being preventative, which I think is quite tragic because there is lots of ... if you don't integrate sort of preventative curative resources it's not a great service really.' (GP, M6)

A few health visitors saw themselves as offering an alternative approach to the GP, assuming that GPs adopted a biomedical approach, prescribing antidepressants:

'I find quite often though they say they don't want to come and see the doctor and they don't want to have medication ... and then I would end up going and seeing them at home, regularly for a little bit, just offering support, just being there for listening.' (HV, B3)

Many health visitors expressed negative attitudes to, and experiences of working with, GPs, and made assumptions about the limited role the GP could play in the management of a woman with postnatal depression:

'The GPs, and I think they're even worse than we are because they, from experience of women l've visited, they just write a prescription, put them on antidepressants.' (HV, M2)

'Not with all the GPs, no, as I say, you know, sometimes the GPs are, they don't have a very sympathetic attitude to postnatal depression, let's say. And so I would imagine it puts the mothers off going to see them actually. And then hopefully they'll come and see us, but I'm sure there's some who don't, you know.' (HV, L5)

\section{Ways of working}

Recent reorganisation and the introduction of corporate working had affected health visitors' perceptions of their relationships with both GPs and women:

'The [patient's] notes go back into the pot and if anything arises in the future it's whoever's around to deal with it, whoever gets allocated. That's what they call corporate working.' (HV, B4)

'For the vast majority of them we don't [see them again], we're not able to offer even a routine follow-up visit, even if it's their first baby. We explain the situation to them in terms of staff and resource, and we encourage them to come to clinic or to phone us, and we explain that we do visit some families at home and offer them extra support. However, in terms of listing the priorities I would say the postnatally-depressed ones aren't high up on the agenda. When we've got much more prioritised.' (HV, M5)

Other health visitors commented on the effect of physical isolation that had accompanied the move to corporate working:

'I personally don't think health visitors know their families like they, like you used to know them. You'd perhaps, er, you'd have a geographical patch and knew everybody ... we'd meet on the street and, I think, you know, especially since we've been moved right out of the areas.' (HV, L4)

'Working corporately, we all work between the GPs and as work comes in we allocate families ... the only downside, I would say, I mean it's the families aren't becoming reliant on you, that's the good thing.' (HV, M1)

The health visitor quoted above justified the lack of continuity of care by stating that families could not become dependent on her.

GPs were aware of these changes in the organisation of health visiting services and described the impact on their day-to-day relationships with health visitors, as well as confusion over the expected roles and responsibilities of the health visitor:

'That's another difficulty because the set up of health visitors is being reorganised so where we used to have a health visitor who was assigned to us, who we could discuss cases with, we are now assigned to a local team, so it could be anybody and it could change from day to day who the patient's health visitor is and which team they are working for. Which makes it very difficult to work, and I see no sense in it. Also, they seem to have dropped a lot of their duties in relation to new mothers. And, I do wonder what health visitors are doing now.' (GP, M7)

'I would say that of all the practitioners here they are the least integrated and they are the least, 
erm, we get least communication with them ... there's nothing wrong with them, they're perfectly nice and friendly, but there's just not that clinical sort of connectiveness really.' (GP, B3)

'In the old days I would have said, you know, there's an ongoing relationship with the health visitor, would have said "fine", you know, they can monitor her, they can keep an eye on her that's what she used to do, you know, keep in close contact.' (GP, L1)

The GP above vividly describes the change that he experienced with the move to health visitor corporate working, from a time when a health visitor was attached to the primary care team and would visit women before and after birth, and offer support and practical advice, and how this has perceived to have changed.

\section{Whose responsibility is the management of postnatal depression?}

While a few GPs talked about the pivotal role they perceived health visitors play in the detection and management of women with postnatal depression, most alluded to the recent reorganisation and change in role, with a perception that women with postnatal depression go undetected. Other GPs described their experience of health visitors declining to support women with what was dismissed as a 'mental health problem', although they agreed that health visiting teams still had a role in offering practical support to women with postnatal depression:

'Well, our health visitors tend to say that it's a mental health problem "nothing really to do with me", which is disappointing really. They do go in and offer support but it's very vague what that support is. They cover some practical things around sort of nursery services for the children, stuff like that and it depends which health visitor team it is because not all will take an interest.' (GP, M7)

Some health visitors suggested that there was little point in identifying women with postnatal depression, justifying this with the view that they had nothing to offer women themselves and no resources to refer women to:

'In an ideal world we'd want to pick them up and then offer them more support, but we can't do that. So there's almost this ethical dilemma of well is there any point in identifying them if you can't do anything with them other than send them to the GP for antidepressants, which isn't good, you know?' (HV, M5)

The view expressed by health visitors that there is limited value in referring a woman back to the GP is seen again in these data. Health visitors suggested that, because of the way they worked or staffing issues, the detection and management of women with postnatal depression was no longer a priority for them:

'... at the moment we're short-staffed, so we're really on priority cases at the moment.' (HV, M1)

And a few health visitors described negative aspects of providing support to women with postnatal depression with a risk of dependence on them:

'... you cannot emotionally and mentally prop somebody up for years and years, it's got to end ... sounds awful, doesn't it?' (HV, B4)

So both GPs and health visitors reported that the current systems within which they work constrain the care that can be provided to women at risk of postnatal depression. Some health visitors no longer viewed the management of women with postnatal depression as an integral part of their work.

\section{DISCUSSION}

\section{Summary of main findings}

The importance of knowing the patient and taking a psychosocial approach in making the diagnosis of postnatal depression is seen in the GP narratives, which also highlight the importance of a long-term relationship with the woman. Health visitors did not see that it was in their remit to make a diagnosis of postnatal depression. Some health visitors felt that the label of postnatal depression might be useful, giving a certainty and legitimacy to the symptoms, but many health visitors felt that if this diagnosis meant referring the patient back to their GP, then the only management on offer would be antidepressants, which they felt would not be wanted by women. Each group of health professionals (GPs and health visitors) described perceptions of each other's roles, observing that the move to corporate working had affected their relationships with each other, reduced home visiting by health visitors, and reduced continuity of care. In addition, health visitors described prioritising 'vulnerable families' - but did not identify families in which the mother has postnatal depression as vulnerable. There was agreement between GPs and health visitors that the clinical diagnosis of postnatal depression should be made by the GP, but both parties seemed to fail to 
take responsibility for detection of symptoms of postnatal depression, with GPs assuming that health visitors are responsible, and health visitors justifying a reduced responsibility because of their changed way of working.

GPs do see postnatal depression as a primary care problem, but make assumptions about the role that health visitors play in the management of these women. Some health visitors, however, see postnatal depression as a mental health problem and describe referring women with postnatal depression to the (primary care) mental health team or back to the GP, rather than feeling comfortable to manage women themselves.

Responders described how national policy and local organisational changes were having an impact on patient care, with no individual taking overall responsibility for the care of women with postnatal depression.

\section{Strengths and limitations of the study}

This paper reports a qualitative study embedded in a randomised controlled trial. The use of qualitative methods allows practitioners to raise issues that are of concern to them, and an inductive approach ensures that findings are related to the views articulated. The data were gathered from GPs and health visitors drawn from a large geographical area (nine PCTs). Using researchers from different professional and academic backgrounds to analyse the data is a recognised technique for increasing the trustworthiness of the analysis. ${ }^{27}$

Only health visitors and GPs who were already involved with the RESPOND trial were interviewed (being a stipulation of the ethics committee). PCTs participating in the RESPOND trial did not have a well-established pathway of care for postnatal depression, thus participating PCTs may have a poorer provision of services, and attitudes of the health professionals working in these areas will reflect this. The findings may, therefore, not be representative of (even neighbouring) PCTs, which may have developed a postnatal depression strategy and services for this group of patients.

\section{Comparison with existing literature}

Responders views on the aetiology of postnatal depression resonate with the literature where there is ambivalence about the nature of 'depression', $8^{9} \mathrm{~A}$ similar view about postnatal depression is reflected by GP responders, with a lack of agreement about the labelling and management of the condition. Health visitor responders seem as unprepared as practice nurses have been reported to be in the management of postnatal depression. ${ }^{29}$ It is difficult to know whether GPs and health visitors were also reluctant to make a formal diagnosis of postnatal depression because of a perceived lack of resources to which to refer women, as seen in other studies. ${ }^{7,28}$

It has been recommended that health visitors should carry out screening for postnatal depression, ${ }^{30}$ although other commentators dispute that this is appropriate. ${ }^{31}$ Health visitor narratives did suggest that they struggled with their diverse roles and had a lack of clarity over the concept of postnatal depression, ${ }^{32}$ experiencing conflict between their roles in respect of infant and mother. ${ }^{8}$ Corporate working ${ }^{21}$ and altered priorities have reduced health visitor contacts with women, and there was no rhetoric in the health visitor narratives about valuing relational continuity; all health visitors justified this way of working by describing how this would prevent families developing dependency or reliance on them.

\section{Implications for future research and clinical practice}

The NICE guidelines suggest the establishment of a specialist multidisciplinary perinatal service in each locality to provide direct services, consultation, and advice to maternity services, other mental health services, and community services. ${ }^{4}$ Such specialised services can improve care through the introduction of protocols and care pathways, educational initiatives, and training for primary care teams. In addition, such teams would provide a service for GPs and health visitors to refer women to, since it seems that not having such a service can become a barrier to making the diagnosis of postnatal depression. The results suggest that this would be the appropriate way forward if health visitors no longer feel ownership over postnatal depression but could, of course, lead to the danger of further fragmentation of care. ${ }^{22}$

The concept of a social model of postnatal depression adopted particularly by GPs would suggest that programmes such as Sure Start might be appropriate to contribute to the management of women with postnatal depression, but evaluation of such programmes has been disappointing, ${ }^{25}$ particularly in socially deprived areas, where some of the responders worked.

\section{Funding body}

The study was funded by the HTA, Department of Health (grant number 02/7/04). The views expressed in the paper are not necessarily those of the funders

\section{Ethics committee}

This study was approved by Scotland A MREC Committee (MREC/03/0127), three local research ethics committees, and research governance agreement from participating PCTs in Bristol, Manchester, and London

\section{Competing interests}

The authors have stated that there are none 


\section{Acknowledgements}

The RESPOND team: lan Anderson, Kathryn Abel, Carolyn Chew-Graham, Elizabeth Chamberlain, Sandra Elliot, Liz Folkes, Louise Howard, Glyn Lewis, Anne McCarthy, Anita Mehay, Jean Mulligan, Tim Peters, Debbie Sharp, Morag Turnbull, Katrina Turner, Andre Tylee, and Alison Warburton. Thank you to those primary care professionals who participated in the trial and agreed to be interviewed. Thank you to Clare Richards who carried out some of the data collection.

\section{Discuss this article}

Contribute and read comments about this article on the Discussion Forum: http://www.rcgp.org.uk/bjgp-discuss

\section{REFERENCES}

1. Department of Health. National service framework for mental health. London: Department of Health, 1999. http://www.dh.gov.uk/en/Publicationsandstatistics/Publications/Pu blicationsPolicyAndGuidance/DH_4009598 (accessed 20 Nov 2007)

2. Hay D, Pawlby S, Sharp D, et al. Intellectual problems shown by 11year-old children whose mothers had postnatal depression. J Child Psychol Psychiatry 2001; 42(7): 871-890.

3. Cox JL, Murray D, Chapman G. A controlled study of the onset, duration and prevalence of postnatal depression. Br J Psychol 1993; 163: $27-31$.

4. Department of Health. Antenatal and postnatal mental health. NICE guideline 45. London: Department of Health, 2007.

5. Edge D, Rogers A. Dealing with it: Black Caribbean women's response to adversity and psychological distress associated with pregnancy, childbirth, and early motherhood. Soc Sci Med 2005;
61(1): 15-25.

6. Pilgrim D, Dowrick C. From a diagnostic-therapeutic to a socialexistential response to 'depression'. Journal of Public Mental Health 2006; 5: 6-12.

7. Chew-Graham CA, May CR, Cole H, Hedley S. The burden of depression in primary care: a qualitative investigation of general practitioners' constructs of depressed people in primary care. Primary Care Psychiatry 2000; 6(4): 137-141.

8. Lloyd B, Howe P. Solutions forgone? How health professionals frame the problem of postnatal depression. Soc Sci Med 2003; 57(10): 1783-1795.

9. While AE. The early history of health visiting: a review of the role of central government (1830-1914). Child Care Health Dev 1987; 13(2): 127-136.

10. Welshman J. Family visitors or social workers? Health visiting and public health in England and Wales 1890-1974. Int Hist Nurs J 1997; 2(4): 5-22.

11. Billingham K, Morrell J, Billingham C. Reflections on the history of health visiting. Br J Community Nurs 1996; 1(7): 386-392.

12. Elliott SA, Gerrard J, Ashton C, Cox JL. Training health visitors to reduce levels of depression after childbirth: an evaluation. J Ment Health 2001; 10: 613-625.

13. Elliot S, Leverton T, Sunjack M, et al. Promoting mental health after childbirth: a controlled trial of primary prevention of postnatal depression. Br J Clin Psychol 2000; 39(Pt 3): 223-241.

14. Davie BR, Howells S, Jenkins M. Early detection of PND in primary care. J Adv Nurs 2003; 44: 248-255.

15. Murray L, Carothers AD. The validation of the Edinburgh Postnatal Depression Scale on a community sample. Br J Psychiatry 1990; 157: 288-290.

16. Cooper PJ, Murray L. Postnatal depression. BMJ 1998; 316(7148): 1884-1886.

17. Holden JM, Sagovsky R, Cox JL. Counselling in a general practice setting: controlled study of health visitor intervention in treatment of postnatal depression. BMJ 1989; 298(6668): 223-226.

18. Boath E, Henshaw C. The treatment of postnatal depression: comprehensive literature review. J Reprod Infant Psychol 2001; 19(3): 215-248.

19. Cowley S. In health visiting, a routine visit is one that has passed. $J$ Adv Nurs 1995; 22(2): 276-284.

20. Department of Health. Chief Nursing Officer's review of the nursing, midwifery and health visiting. London: Department of Health, 2004

21. Houston A, Clifton J. Corporate working in health visiting: a concept analysis. J Adv Nurs 2001; 34(3): 356

22. Derrett C, Burke L. The future of primary care nurses and health visitors: Increasing fragmentation threatens the primary healthcare teams. BMJ 2006; 333(7580): 1185-1186.

23. Young L. Community nurses, social enterprise and community interest companies. Primary Health Care 2006; 16(6): 12-13.

24. Netmums. http://www.netmums.com/h/f/HOME/home/ (accessed 15 Jan 2008).

25. Belsky J, Melhuish E, Barnes J, et al. Effects of Sure Start local programmes on children and families: early findings from a quasiexperimental, cross sectional study. BMJ 2006; 332(7556) 1476-1481.

26. Strauss A. Qualitative analysis for social scientists. Cambridge: Cambridge University Press, 1986.

27. Henwood KL, Pidgeon NF. Qualitative research and psychological theorizing. Br J Psychol 1992; 83(Pt 1): 97-111.

28. May CM, Allison G, Chapple A, et al. Framing the doctor-patient relationship in chronic illness: a comparative study of general practitioners' accounts. Sociol Health Illn 2004; 26(2): 135-158.

29. Naji S, Gibb J, Hamilton RJ, et al. How ready are practice nurses to participate in the identification and management of depressed patients in primary care? Primary Care Mental Health 2004; 2(1): $47-54$.

30. Davie BR, Howells S, Jenkins M. Early detection of PND in primary care. J Adv Nurs 2003; 44: 248-255.

31. Oates M. Postnatal depression and screening: too broad a sweep? $\mathrm{Br}$ J Gen Pract 2003; 53(493): 596-597.

32. McConnell J, Baker M, Marks L. Experiencing a dilemma accounts of working with PND. Community Pract 2005; 78(7) 251-254. 